\title{
KEPEMIMPINAN PEREMPUAN DALAM PELAYANAN GEREJA
}

\author{
Oleh: Clarisa Jane Rahmania Ampang \\ Institut Agama Kristen Negeri Toraja
}

\begin{abstract}
Abstrak:
Secara umum gereja-gereja Liberal menerima keberadaan perempuan sebagai pemimpin dan menempatkan kesejajarannya dengan laki-laki. Tidak bisa disangkal dunia saat ini gencar menuntut kesetaraan laki-laki dan perempuan sebagai akibat konsekwensi implimentasi demokrasi. Namun sehebat apapun demokrasi di suatu Negara, demokrasi tidak bisa mengubah dan menghancurkan kebiasaan dan budaya suatu daerah dalam hal kesetaraan laki-laki daperempuan. Diskriminasi terhadap gender gencar dibicarakan dalam pelayanan digereja.

Banyak yang menolak adanya pelayanan perempuan dalam Gereja dan dianggap sebagai orang yang kedua dalam kepemimpinan di Gereja. Banyak peraturan dan tata gereja yang menolak keleluasaan kepemimpinan
\end{abstract} seorang perempuan dalam Gereja.

\section{PENDAHULUAN}

Pelayanan kaum perempuan dalam Gereja kerap kali menjadi isu yang sering diperdebatkan di antara umat Kristen dan perselisihan pun juga sering terjadi karena masalah ini. Hal ini terjadi karena perempuan dipandang sebagai manusia yang lemah dan tidak mempunyai arti apa-apa dalam sebuah kepemimpinan. ${ }^{1}$. Akan tetapi tak dapat di pungkiri di tengah dunia saat ini yang semakin maju di berbagai bidang, perempuan justru memiliki peran yang tak kalah penting dari laki-laki. Bahkan dalam persekutuan-persekutuan dalam Gereja lebih dominan perempuan di banding laki-laki.

Tetapi sejatinya, kekristenan sebagai lembaga tidak melihat perbedaan martabat laki-laki dan perempuan secara structural. Seperti yang diwacanakan oleh DGD: - Kita menegaskan bahwa perempuan dan laki-laki diciptakan dalam citra Allah. Kita menegaskan harkat dan

\footnotetext{
${ }^{1}$ Rannu Sanderan, 'JABATAN GEREJAWI DAN PERAN PEREMPUAN DALAM PELAYANAN GEREJA'

$<$ https://doi.org/10.31219/OSF.IO/JTCAG>.
} 
martabat yang sama bagi semua orang dan semua ras. Kita menegaskan bahwa hak asasi manusia diberikan oleh Allah $\|^{2}$

Hal yang akan di jabarkan dalam makalah ini adalah Peran, Perempuan dan Pelayanan . Yang pertama peran dalam Kamus Besar Bahasa Indonesia artinya ikut ambil bagian dalam suatu kegiatan yang dilakukan secara aktif. ${ }^{3}$ Yang kedua adalah Perempuan atau wanita adalah seseorang yang berlawanan jenis dengan laki-laki. Yang terakhir adalah mengenai pelayanan yang berasal dari kata benda -pelayanl yang memiliki arti -orang yang melayanil berubah menajdi kata kerja -melayanil yang berkaitan dengan pekerjaan dan berubah lagi menjadi -pelayananl. Jadi dapat dikatakan bahwa pelayanan adalah suatu hal dalam melayani kegiatan yang hasilnya di tujukan untuk keinginan orang lain, baik individu ataupun kelompok serta masyarakat. ${ }^{4}$

\section{TUJUAN DAN MANFAAT}

Agar jemaat dan masyarakat memahami bahwa ternyata perempuan juga memiliki peran yang cukup penting baik dalam pelayanan di Gereja. Hal ini di kaji agar orang khususnya warga jemaat memahami bahwa perempuan juga memiliki potensi dan mampu untuk menjadi seorang pemimpin dan pelayan di lingkup gerejewi . Karena harkat dan martabat perempuan tak kalah penting daripada laki-laki.

\section{PEMBAHASAN}

\section{A. Ajaran Alkitab Tentang Peran Perempuan dalam Gereja}

Di dalam Alkitab, baik dalam Perjanjian Lama maupun Perjanjian Baru terdapat ajaran mengenai peran perempuan yang tak kalah pentingnya dari peran laki-laki. Hal ini menunjukkan bahwa memang sedari dulu perempuan juga diberi suatu tanggungjawab di dalam suatu kepemimpinan dan dianggap istimewa.

Di awal penciptaan memang sudah dijelaskan mengenai keistimewaan seorang perempuan misalnya dalam Kejadian 1:1-2:4a yang menjelaskan mengenai penciptaan laki-laki

\footnotetext{
2 Sanderan, 'JABATAN GEREJAWI DAN PERAN PEREMPUAN DALAM PELAYANAN GEREJA'.

${ }^{3}$ Nunuk Rinukti Siahaya Sekolah Tinggi Agama Kristen Teruna Bhakti, 'Peranan Perempuan Menurut Perjanjian Baru Bagi Perkembangan Kepemimpinan Perempuan Di Dalam Gereja', JURNAL TERUNA BHAKTI, 1.1 (2019), 33-41 <https://e-journal.stakterunabhakti.ac.id/index.php/teruna/article/view/9> [accessed 2 December 2021].

4 'V Pelayanan : Pengertian, Tujuan, Fungsi, Unsur \& Jenis' <https://seputarilmu.com/2019/11/pelayanan.html> [accessed 3 December 2021].
} 
dan perempuan yang diciptakan sesuai dan segambar dengan rupa Allah. Keduanya di lihat sebagai ciptaan yang baik, yang satu tidak lebih rendah dibanding yang lain keduanya sama- sama diberkati oleh Allah. ${ }^{5}$ Menjadi penolong yang sepadan berarti keduanya sama-sama diberi tugas atau mandate dan tanggungjawab dalam mengelola seluruh alam ciptaan Allah. Jadi tidak ada pembedaan di antara keduanya. Akan tetapi banyak orang yang menafsirkan atau memahami salah mengenai kata -:penolong| mereka beranggapan bahwa kata penolong ini adalah pembantu.

Selain tokoh di atas terdapat juga beberapa tokoh yang memiliki peranan yang cukup signifikan dalam sejarah umat Tuhan yakni Rahab,Rut,Debora,dan Ester. Misalnya secara keseluruhan dalam Kitab Rut dijelaskan mengenai Rut yang adalah seorang Moab dimana ia diapandang sebagai orang kafir dan hina oleh Kaum Yahudi. Tetapi meskipun demikian ia tetap memperlihatkan bahwa ia cukup mengerti akan firman Tuhan. ${ }^{6}$

Dalam Perjanjian Baru juga ditemukan beberapa wanita yang secara tersurat maupun tersirat berperan dengan baik dalam melayani maupun membantu pelayanan para pelayan Tuhan pada saat itu yakni Maria, Elisabet,Lidia, Friskila, dan Febe. ${ }^{7}$

\section{B. Persoalan mengenai Jabatan kaum Perempuan dalam Gereja}

Dalam Gereja ada saja konflik mengenai peran seorang perempuan. Bahkan ada isu mengenai jemaat yang menolak pendeta atau proponen perempuan. Hal ini dikarenakan banyak yang menganggap wanita sebagai seorang yang lemah, tidak tegas dan tidak terlalu dapat diandalkan. Mungkin sama halnya dengan adanya pengaruh stratifikasi sosial dalam memilih dan menetapkan pemimpin dalam gereja, yakni bahwa seorang pemimpin itu harus pintar, berani,kaya dan mempunyai status yang cukup besar. Sehingga dalam menetapkan pelayan bukan jiwa pengutusan yang telah diterima melainkan cenderung stratifikasi sosial dominan

\footnotetext{
5 'Perempuan-Perempuan Dalam Alkitab - Google Books' <https://books.google.co.id/books?id=IdSmWRPoS8AC\&pg=PR\&\&dq=peran+perempuan+dalam+gereja\&hl=jv\&sa= X\&ved=2ahUKEwiPt9HPgcX0AhVWUGwGHaCXAV4Q6AF6BAgLEAI\#v=onepage\&q=peran perempuan dalam gereja\&f=false $>$ [accessed 2 December 2021].

6 'View of Pemahaman Tentang Sayap Dalam Kitab Rut' <https://kamasean.iakntoraja.ac.id/index.php/ojsdatakamasean/article/view/33/16> [accessed 1 December 2021].

7 Rinukti Siahaya Sekolah Tinggi Agama Kristen Teruna Bhakti.
} 
menjadi acuan dasar dalam menerima pelayanan dalam Gereja. ${ }^{8}$ Jadi yang diprioritaskan itu bukanlah kesiapannya dalam melayani melainkan status sosialnya. Sudah saatnya bahwa Gereja harus mengubah pola kepemimpinan yang lama dimana kaum perempuan dianggap sebagai orangorang yang lemah dan tidak dapat memegang jabatan dalam kepemimpinan. ${ }^{9}$ Harusnya yang dilihat bukan soal kuat atau lemahnya seorang perempuan tetapi bagaimana ia mengimani tugas panggilannya. Faktanya adalah bahwa kepercayaan atau iman seseorang itu dipengaruhi dari cara berpikir,perilaku,sikap nilai yang tercermin dari seseorang atau dengan kata lain kultur bukan dari lemah atau kuatnya seseorang. ${ }^{10}$

Sejarah mencatat bahwa bahwa kepemimpinan di kalangan Gereja lebih banyak di pegang oleh laki-laki daripada perempuan. Hal ini di akibatkan oleh tiga faktor yakni alasan teologis, alasan budaya dan alasan praktis. Ketiga hal ini memberi pengaruh yang cukup tinggi terhadap pemahaman warga jemaat. Contoh dalam praktik budaya Toraja cenderung menempatkan kaum perempuan sebagai kaum lemah daripada kaum laki-laki. ${ }^{11}$ Di dalam masyarakat Toraja memang jarang ditemukan perempuan yang menjabat sebagai pemimpin seperti halnya parengnge ${ }^{6}$, to mina dan sebagainya karena yang dianggap paling mengerti adat dan aluk adalah kaum laki-laki. Oleh karena itu saat ini harus di mulai pemikiran yang baru bahwa laki-laki dan perempuan itu memiliki kesetaraan. Masing-masing orang harus di beri kesempatan untuk berbicara dan mendengar dalam kapasitas yang setara dan sejajar serta kesadaran bahwa masing-masing pihak mengungkapkan kebenaran yang patut untuk di pertimbangkan. ${ }^{12}$

\footnotetext{
8 Rannu Sanderan, 'STRATIFIKASI SOSIAL, Kepemimpinan Tradisional Toraja Dalam Dinamika Demokrasi Modern' <https://doi.org/10.31219/OSF.IO/63YAJ>.

${ }^{9}$ Sanderan, 'JABATAN GEREJAWI DAN PERAN PEREMPUAN DALAM PELAYANAN GEREJA'.

${ }^{10}$ Rannu Sanderan, 'EXEMPLARY, MENEMUKENALI KUNCI PENDIDIKAN IMAN BAGI ANAK DALAM KELUARGA DAN PEMBELAJARAN AGAMA DI SEKOLAH' <https://doi.org/10.31219/OSF.IO/BMTRK>.

${ }^{11}$ Sanderan, 'JABATAN GEREJAWI DAN PERAN PEREMPUAN DALAM PELAYANAN GEREJA'.
} 


\section{KESIMPULAN DAN SARAN}

Dalam Alkitab baik Perjanjian Lama dan Perjanjian Baru kaum perempuan memang sudah diberi tugas dan tanggungjawab yang sepadan dengan laki-laki karena keduanya di ciptakan untuk mengelolah alam ciptaan Tuhan. Tidak ada pembedaan di antara laki-laki dan perempuan. Namun karena pola pikir dari warga jemaat yang dipengaruhi oleh faktor teologis, budaya dan praktis akhirnya terjadilah pembedaan gender yang cukup signifikan di dalam kepemimpinan dalam Gereja. Pelayanan kaum perempuan dianggap lemah, dan tidak tegas dibanding pelayanan kaum laki-laki. Tugas dan tanggungjawab setiap orang Kristen harus dimulai dengan sikap yang baru yakni perlakuan yang adil di antara laki-laki dan perempuan. Yang perlu diperhatikan adalah kesiapannya dalam melayani bukan dari status sosialnya ataupun kemampuan dari segi kuat atau lemahnya dalam menjadi seorang pemimpin. Harkat dan martabat dalam diri seseorang adalah pemberian dari Tuhan dan tidak boleh ada seorang pun yang mampu menguranginya atau memanipulasinya. Jadi, dalam perkembangan zaman sekarang ini warga jemaat harus menyadari adanya kesetaraan antara laki-laki dan perempuan sehingga tidak terdapat lagi diskriminasi gender. 


\section{DAFTAR PUSTAKA}

Sanderan, Rannu,_EXEMPLARY, MENEMUKENALI KUNCI PENDIDIKAN IMAN BAGI ANAK DALAM KELUARGA DAN PEMBELAJARAN AGAMA DI SEKOLAH ${ }^{\circ}$ <https://doi.org/10.31219/OSF.IO/BMTRK>

— _JABATAN GEREJAWI DAN PERAN PEREMPUAN DALAM PELAYANAN GEREJA'<https://doi.org/10.31219/OSF.IO/JTCAG>

___STRATIFIKASI SOSIAL, Kepemimpinan Tradisional Toraja Dalam Dinamika Demokrasi Modern'<https://doi.org/10.31219/OSF.IO/63YAJ>

=View of INTUISI: Pendalaman Gagasan Hans-George Gadamer Tentang Intuisi Sebagai Supralogika $\quad<$ https://ojs-jireh.org/index.php/jireh/article/view/39/36> [accessed 1 December 2021]

=View of Pemahaman Tentang Sayap Dalam Kitab Rut ${ }^{\star}<$ https://kamasean.iakntoraja.ac.id/index.php/ojsdatakamasean/article/view/33/16> [accessed 1 December 2021] 